\title{
REORIENTING MANAGEMENT EDUCATION TO MEET CORPORATE EXPECTATIONS
}

\section{Dr. Jasmine Gupta}

\begin{abstract}
$\underline{\text { Abstract }}$
Management Education in India has come of age. The focus of management education is to serve twin purposes, one, to provide a functional and vocational orientation to the management students by preparing them mentally and technically for their careers. The second aim is to provide a general management education based on humanities, social sciences and ethics. However, since the last decade the forces of globalization, deregulation, open competition, privatization and technological change that have made a profound impact on society and business should also affect the context in which business education takes place in the next decade. Furthermore, global businesses call for management talents with global decision-making and executive capability. The pertinent question in such a scenario is whether our management institutions are really grooming the type of managers required by the corporate or not. Thus it is very important to understand the expectations of corporate from business schools because these schools are almost like laboratories incubating the future managers who would lead our future organizations. Thus B-schools would need to introspect and re-examine the roles they are performing at present, and reorient their focus for a large perspective. The objective of the paper 'Reorienting Management Education to meet Corporate Expectations' is to highlight the current situation of management education in India and focus on the point that business schools should reorient their management education approach to enhance the competencies of their managers to meet corporate expectations.
\end{abstract}




\section{$\underline{\text { Introduction }}$}

Education is the learning process by which values, attitudes, information and skills are acquired and integrated. Management Education is the process of learning values, attitudes, information and skills to achieve desired relations between resources and objectives (Chaudhary N. R., 17). Moreover, management is a science, which requires art to practice it and involves values, attitudes, techniques and behavioral patterns at both strategic and practical levels. Different types of organizations call for different types of management and different situations within a particular organization require specific skills.

\section{Management Education}

The basic objective of management education is to produce skilled manpower required by the industry in different economic sections. It aims at improving the quality and productivity of personnel in the business area at a desired level.

However, currently, management education in the global world communities and markets is witnessing two significant developments. Firstly, the whole world has understood the importance of ecologically-sustainable development and secondly, the globalization of markets is causing a transformation in the way in which organizations compete and develop their business processes. And education does not stand apart from the societal and organizational changes. The forces of globalization, deregulation, open competition, privatization and technological change that have an impact on society and business are significant factors affecting the context in which business education occurs in the next decade (Keller Thomas F., 48). Moreover, the technological revolution, the internet, which is now able to embrace the technologies of communication, audio and video, will significantly change the boundaries of what is feasible in education access and delivery (Sinha Dharni, 30).

In India, the limits of the governments' capacity to find exploding demands for management education have already been stretched. With the entry of the private sector, business schools in India have already moved into the commercial generation of income through higher fees and executive development courses. There has been a quantum jump in the number of management 
schools in India and subsequently many of them have closed down too due to manifold problems.

However, the current mindset of management education is largely focused on the clustering of staff and students in one geography location for classroom tuition, and largely assumes that the customers, i.e. the students will like to complete management qualifications at an early stage of life, in preparation for the management career during which they will expect to apply some of the knowledge and skills they have learned. The changing context however would require a conceptual shift to a new style of access and delivery, as feasible, and no argument can be advanced that our customers will not want it to occur.

\section{Objectives}

The Objectives of this paper is to highlight the current situation of management education in India, the performance of current B-school graduates, the expectations of corporates from management graduates and the reorientation required in management education in light of the skill requirements and expectations to meet challenges effectively at a global level.

\section{Research Methodology}

To fulfill the above objectives, Qualitative research was carried out using in-depth interviews of 26 top-notch executives of reputed corporate recruiters at various B-schools, who were sampled using judgement sampling.

\section{Management education in India: Progress in the right direction?}

With the mushrooming of management institutes and consequent competition and technology enhancement, the pertinent question that whether such management education is relevant to actual reality in the industry and workplace has become of paramount importance and it requires lot of changes in course curriculum, pedagogy and also delivery.

Though teaching, learning and research may remain as core activities, the real responsibility of the institute is to create a value added student resource, which the employers may consider 
useful. For instance, if a management graduate however knowledgeable or smart he may be, if he is not useful in actual work place, then the institute which trained him should take some responsibility for his failure. An MBA joins a Trading House where he is told to develop new business and guide others through every step for developing new business. But, he realizes soon that he is on his own. He begins to feel restless- Can he really develop any new business? Does he have the genius? What happens if he fails?

The above situation occurs when the management education has not been considered as a part of practical business. It needs lot of practical training and exposure. Only bookish knowledge will not suffice for a business graduate.

In the perspective of the business graduates, several factors contribute to their dissatisfaction in the jobs. It could be due to mismatch in initial perceptions about the company, it could be peer pressure, better compensation and career growth being enjoyed by the peers and possible geographical preferences. Perhaps not well known, there is also an element of using the jobs provided by the campus recruiters strictly as a launch pad.

In this scenario, the concern for the B-School Professors should be how to cultivate good business leaders with the attributes of increased efficiency and effectiveness, ethics, knowledge, who can take responsible roles in their organizations and society, possess the fluency to apply management concepts, theories and tools, and how to arrive at a good fit between the aspirations of their students and the need of the companies.

Unfortunately, however, only a handful institutes in our country have paid attention to this crucial issue. Most of the universities' business management departments, which do produce a good chunk of management graduates, are badly lacking in the pre-requisites of a good business management institute itself (Dhankar R. S., 51). To add to this, there is a complete mismatch between what is being taught in business schools and the requirements of the business organizations. 
It is also observed that at present in most of the business organizations, MBAs are facing their biggest challenge. The utility, reliability, and efficacy of MBAs is being seriously questioned by the companies and are wondering whether it makes economic sense in employing young MBAs at such mind boggling salaries. Are the MBAs really as smart and as intelligent as they are projected to be? Do they have the necessary skills and expertise to give good delivery on the job? Hence, before these doubts are confirmed, people associated with management education should reorient and revamp the learning that is being imparted at most business schools today.

\section{$\underline{\text { Reorienting Management Education }}$}

As discussed in the previous section it is very important to understand the expectations and requirements of business organizations from business schools because these schools are almost like laboratories incubating the future managers who would lead our future organizations. It is very necessary to bridge the gap between what is being taught and what has to be practiced in reality.

To get a feel of what organizations feel about the MBA graduates and what they really expect them to be, the author had conducted in-depth interviews with representatives of reputed corporate recruiters at various B-schools. Nearly 26 top-notch executives from various corporates were sampled using judgement sampling for the interviews. The theme of the interview was - How to bridge the gap between management education framework and requirements of business organizations as well as their expectations related to the qualities that management graduates should possess?

On the basis of the discussions held during the interviews and the above analysis of changes in the society and organizations the researcher strongly feels that there is an emergent need to reorient management education by incorporating (a) a holistic approach; (b) an ethical approach and (c) a co-operative learning approach. A holistic view of organizations requires institutions to adopt a systems approach and understand the interdependences in relation to the changing organizational environment. The ethical approach requires that institutions take into consideration the social goal of an ecologically sustainable society and the importance of inculcating ethics into their students. A cooperative learning approach requires creating learning 
teams continuously evolving quality service, reinventing organizations, and transforming the knowledge so obtained into action. Management institutions need to inculcate all these approaches in their students while preparing them for their management career.

Moreover research clearly indicated that several other competencies would be required to be cultivated in the management talent pool apart from the basic managerial qualities since the winner would be the one who would be able to stand apart clearly and differentiate oneself as a leader amidst all. These competencies, which surfaced on the basis of analysis of the discussions held during the interviews, have been outlined below in brief:

- In this information age of organizations, business schools would have to make their graduates multi-skilled and having interdisciplinary knowledge as well. Highly specialized knowledge would make them focused but it would lead to development of a narrow view of how organizations work and also make them skilled in only a particular area.

- Earlier organizations used to be reactive in solving problems as they emerged - a short-term focus dominated by the bottom line. However with changes in environment as discussed above they have become more proactive. Thus b-schools would have to train their graduates to become very practical and proactive in anticipating issues before they can become crises a balance has to be achieved between short-term pragmatism and long-term purpose.

- B-graduates would need to learn to be more flexible in accepting different roles, responsibilities and positions at their workplace.

- B-schools would need to make their students learn to work in a cohesive way with different teams and be accountable for their teams since team performance and accountability is given more preference in organizations today than individual accountability.

- Organizations no longer focus on measurable outcomes today using inspection and an autocratic leadership style. Rather their focus is on strategic issues and stakeholder satisfaction and use a participative leadership style giving importance to employee empowerment as well. B-schools would need to nurture their future managers to instill this style of leadership from the very beginning. 
- A b-school student is usually very present oriented, doing what is known now. Business schools need to instill the thought that he should be future oriented and prepare him for the future.

- B-schools should place more emphasis on experiential learning wherein the students learn by doing things themselves. They should be allowed to actively participate in institutional development, made to plan and organize educational events and seminars, prepared to take leadership roles in various committees working for institutional and students' development, made to plan how to maintain continuous liaison with corporate and allowed to plan and implement their own placement activities. All these would help them to get a hands-on experience towards various management functions, which they learn in the classroom and develop various managerial skills that would be required when they move out to set their career in the corporate world.

\section{Reorienting Business Schools' Philosophy}

Globalization raises many issues which are relevant to business management. Global businesses call for management talents with global decision-making and executive capability. Thus Bschools would need to reorient their focus and philosophy for a global perspective as outlined below:

- Business schools should broaden the scope of corporate collaboration for more global practices.

- B-schools would be required to explore for multi-lateral collaboration to cultivate future leaders with global vision and capability of utilizing global resources.

- They would to need to engage in more international collaborations for student exchange, faculty training and joint research activities \& projects.

- B-schools would require to have an international orientation in curriculum design, courses \& pedagogy, teaching materials, delivery through multiple modes using technology as a facilitator, selection of permanent \& guest faculty and faculty development to become globally competitive. 
The speed and frequency of change in the field of management education will require highly developed competencies in the management faculty group also. The management educator will also need to become more knowledgeable in developing sensitivities and insights in the effective domain of the customer. The best learning approach would be that the student, as customer, will continue to work in their organization, with the business educator acting as facilitator and mentor in organizationally-focused active learning.

A good business school ultimately has to be judged by the quality of the business leaders and highly competent professional managers it produces. Such schools and their faculty should see their roles as developers of change agents, knowledgeable problem-solvers, creative thinkers, effective team members and team leaders, entrepreneurial risk-takers, and persons who acquire deep theoretical insights with skills to apply them.

The Table 1 given below indicates the changes that management institutes and management educators would be required to bring in their approach towards imparting management education in the society from various points.

Table 1

\begin{tabular}{|c|c|}
\hline Traditional Education Thought & Modern Education Thought \\
\hline 1. Traditional course structure & 1. Courses based on market demand \\
\hline 2. Theoretical education & 2. Experiential education (Action learning) \\
\hline 3. University as a city & 3. University as an idea \\
\hline 4. Terminal degree would end learning & 4. Lifelong learning \\
\hline 5. University as an ivory tower & 5. University as a partner in society \\
\hline $\begin{array}{l}\text { 6. Books as primary medium of } \\
\text { information }\end{array}$ & $\begin{array}{l}\text { 6. Information on demand from various } \\
\text { sources at a simple click }\end{array}$ \\
\hline 7. Student $=2$ or 3 -year revenue source & 7. Student $=$ Lifelong revenue resource \\
\hline 8. Competition is other institutions & 8. Competition is Everyone \\
\hline 9. Student as a Pain & 9. Student as a Customer \\
\hline 10. Delivery in a classroom & 10. Delivery anywhere \\
\hline 11. Multi-cultural approach & 11. Global Approach \\
\hline 12. Single discipline & 12. Multi-disciplinary \\
\hline
\end{tabular}


13. Passive learning

14. Knowledge transfer

15. Question-based exams

16. Technology as an expense
13. Active learning

14. Knowledge creation

15. Project-based assessment

16. Technology as a differentiator

Thus management educators would need to reorient themselves as well as their b-graduates to inculcate several learning approaches such as lifelong learning, just-in-time learning, learnerdriven learning, customized learning, collaborative learning, contextual learning, learning to learn etc. to stay abreast with the changing times. The knowledge economy has brought to the forefront the importance of human capital. While finance and operations, marketing and MIS remain critical to management learning, there is growing recognition that people skills are becoming paramount. Leadership, teamwork, risk-taking and conflict management, attitude and motivation, service orientation and change in mindsets should emerge as centerpieces of curriculum for imparting effective management education in this fast-changing world.

\section{Conclusion}

In order to survive and grow in the current highly competitive and rapidly changing global business environment, the expectations of business organizations from business schools are rising. Organizations today require business leaders and managers with great clarity of thought and vision, well-articulated objectives and priorities, and the ability to inspire people to give their best in highly effective teams. They have to be able to add value at each link of the supply chain and the value chain. They need superior business models to develop a competitive edge. Undoubtedly, some of our b-schools are excellent. But many more are still stuck in the classroom-and-lectures routine. Our management schools should have close interface with corporate organizations and run like our medical colleges - where practical learning and research go hand-in-hand with lessons on theory. The mission of our business schools should be to develop business leaders and entrepreneurs skilled in the tools of international competitiveness and endowed with the global mindset that increasingly typifies management in the twenty-first century. To sum up, our B-schools can groom managers to meet the future challenges only by imparting high-quality education with a practical and international orientation. 
Towards Excellence: An Indexed, Refereed \& Peer Reviewed Journal of Higher Education / Dr. Jasmine Gupta / Page 139-148

\section{$\underline{\text { References }}$}

Chaudhury N. R. "Management in Education", A. P. H. Publishing Corporation, New Delhi, 2001, p. 17

Keller Thomas F. "The evolving MBA", Effective Executive, Issue 84, 1993, p. 48

Sinha Dharni P. “Gaps in B-schools”, Indian Management, vol. 43, no. 1, 2004, p. 30

Mishra R. K. "Patterns of Management Education in India", South Asian Journal of Management, 2002, vol. 9, no. 4, p.36

Dhankar R. S. "Long Summer in Management Education”, Indian Management, 1998, p.51

\section{Dr. Jasmine Gupta}

Vice President, Kotak Mahindra Bank Ltd.

M: 9188796296296

Email: jasmineguptab03@gmail.com 